\title{
EXAMINING URBAN EXPANSION USING MULTI-TEMPORAL LANDSAT IMAGERY: A CASE STUDY OF THE MONTREAL CENSUS METROPOLITAN AREA FROM 1975 TO 2015, CANADA
}

\author{
Lingfei. Ma ${ }^{\text {a }}$, He. Zhao ${ }^{\text {a }}$, Jonathan. $\mathrm{Li}^{\text {a, * }}$ \\ ${ }^{a}$ Mobile Mapping Lab, Department of Geography \& Environmental Management, University of Waterloo, Waterloo, ON N2L 3G1, \\ Canada-153ma@uwaterloo.ca
}

KEY WORDS: Urban Expansion, Remote Sensing, Landsat Imagery, Classification, Change Detection, Driven Forces Analysis, Montréal Census Metropolitan Area.

\begin{abstract}
:
Urban expansion, particularly the movement of residential and commercial land use to sub-urban areas in metropolitan areas, has been considered as a significant signal of regional economic development. In 1970s, the economic centre of Canada moved from Montreal to Toronto. Since some previous research have been focused on the urbanization process in Greater Toronto Area (GTA), it is significant to conduct research in its counterpart. This study evaluates urban expansion process in Montréal census metropolitan area (CMA), Canada, between 1975 and 2015 using satellite images and socio-economic data. Spatial and temporal dynamic information of urbanization process was quantified using Landsat imagery, supervised classification algorithms and the post-classification change detection technique. Accuracy of the Landsat-derived land use classification map ranged from $80 \%$ to 97\%. The results indicated that continuous growth of built-up areas in the CMA over the study period resulted in a decrease in the area of cultivated land and vegetation. The results showed that urban areas expanded $442 \mathrm{~km}^{2}$ both along major river systems and lakeshores, as well as expanded from urban centres to surrounded areas. The analysis revealed that urban expansion has been largely driven by population growth and economic development. Consequently, the urban expansion maps produced in this research can assist decision-makers to promote sustainable urban development, and forecast potential changes in urbanization growth patterns.
\end{abstract}

* Corresponding author 


\section{INTRODUCTION}

Urban expansion, particularly the increase of built-up areas in sub-urban areas in metropolitan areas, has been regarded as an important signal of regional economic development (Yuan et al., 2005). However, along with fast economic development and rapid urbanization process, its benefits are increasingly balanced against environmental impacts (Squire \& Kubrin, 2005), such as the decreasing watersheds, land reclamation, coastline change and prominent food production. Therefore, determining how to balance economic benefits maximum and environmental impacts minimum is a challenging task for decision makers for planning, environmental management and land resources integration in the process of urban expansion (Yuan et al., 2005; Wang et al., 2015).

Remote sensing technology plays a significant role that can provide a great amount of data of the Earth surface (Jensen, 2004). Moreover, satellite images can quantitatively describe the spatial structure of urban environment, and provide a costeffective and visualized tool to detect urbanization footprints (Gutman et al., 2004). Multi-temporal and multi-spectral data can be obtained for analysing and monitoring urban expansion patterns using remotely sensed imagery (Weng, 2002). For example, Alberti et al (2004) indicated that the remote sensing technology has the capability to describe changes of land use based on timely and accurate geospatial data. Furthermore, in combination with geographical information system (GIS) that can provide an effective tool to store, analyse, integrate, and display geographical information (Malczewski, 1999), remote sensing and GIS technologies have been widely applied in detecting land use and land cover changes and monitoring urbanization process over the last decades (Dewan et al., 2009).

In this study, combined with GIS technique, temporal analysis is conducted to detect urbanization process using Landsat series imagery from 1975 to 2015 in the Montréal Census Metropolitan Area (CMA). Six level-2 classes are assigned: residential, commercial, barren cropland, water body, forest, and vegetation. The post-classification comparison change detection approach is applied, necessitating the selection of an appropriate classification algorithm. Since unsupervised classifiers need a great amount of work to refine results during the post-classification comparison period, several supervised classification and machine learning methods have been used, such as Maximum Likelihood Classifier (MLC) (Otuker et al., 2010), Support Vector Machine (SVM) (Schneider, 2012), and Artificial Neural Network (ANN) (Erbek et al., 2004). Compared with traditional classification classifiers (e.g. MLC), the Decision Tree (DT) classifier is a different classification algorithm, which is an ensemble consisting of a large number of diverse criterions aiming to separate and identify various classes (Joelsson et al., 2006). Based on the previous studies, the performance of MLC, SVM, ANN and DT classifiers are tested according to accuracy assessment, and their relative performances are evaluated.

Compared with existing work, there are few studies focusing on urban expansion issue in the Montréal CMA using satellitebased approach. This research intends to examine the dynamic change patterns in the urbanization process of the Montréal CMA over a period of 40 years. Multiple classification approaches are used and urban expansion patterns are evaluated in terms of bi-temporal (i.e. between years) and multi-temporal (i.e. across all years) analysis from Landsat imagery at 5-year intervals from 1975 to 2015 . Consequently, quantitative and qualitative results of the Montréal CMA urban expansion can be examined. The objectives of this study are thus to identify the urban expansion patterns and characterize the potential driving forces contributing to these changes in the CMA using remotely sensed data and socio-economic data. Specifically, the objectives are (1) to map temporal land cover categories through classification of Landsat series imagery; (2) to assess the accuracy of Landsat series classification results derived by applying MLC, SVM, ANN and DT algorithms; (3) to analyse the tendency of urban expansion in CMA, and to evaluate major driving forces that contribute to relevant changes.

\section{METHODOLOGY}

\subsection{Study area}

The study area is the Montréal Census Metropolitan Area shown in Figure 1, which is the second most populous metropolitan area in Canada after the Greater Toronto Area (GTA). This project focuses on the urban expansion and population explosion, according to the Statistics Canada, it reported that the CMA had a population of 3,824,221, an increase of 5.2\% from 2006 (Canada 2011 Census). This leads to a population density of about 898 people per square kilometer. As the total population and population density of the Montréal CMA is increasing rapidly, it is suitable for urban expansion analysis. The time period chosen are from 1975 to 2015 because it is a highly developed period of the area. Therefore, significant changes of urbanization can be seen directly. The Montréal CMA also includes a diversity of land use categories interspersed with large scales of buildings, watersheds and more than hundreds of hills. Both high and low densities of population are found in the specific portions of the Montréal CMA in the past decades (Canada 2011 Census). These features indicate the high potential of urbanization process in the Montréal CMA.

\subsection{Data sources and pre-processing}

Imagery from Landsat-1 and Landsat-2 Multispectral Scanner (MSS), Landsat-5 Thematic Mapper (TM), Landsat-7 Enhanced Thematic Mapper Plus (ETM+), and Landsat-8 Operational Land Imager (OLI) were acquired and mainly used to analyse land cover changes and urban expansion in the Montréal CMA (Table 1). MSS images were resampled to $30 \mathrm{~m}$ resolution, and all reflective bands were applied in image classification excluding the thermal band. All these images were obtained from USGS with level-one product format, sometimes over two images were applied to improve classification accuracy (Table 2). In order to avoid the influence of snow, most of images were acquired from May to October. The World Geodetic System of 1984 (WGS84) and Universal Transverse Mercator (UTM) were selected as coordinate systems. The software Environment of Visualizing Images (ENVI) and ArcGIS version 10.3 were used to conduct image pre-processing. Layer stacking for all images was performed first, followed by images registration. Dark pixel subtraction approach was then used to carry out atmospheric correction based on unique digital number values of each image. Finally, seamless mosaic tool in ENVI was selected for mosaicking images with colour balance, and all mosaicked images were clipped by the boundary of the study area. The Montréal CMA boundary and census division's boundaries were obtained from Statistics Canada (2011).

Census statistical data from 1971 to 2011 provided by Statistics Canada were used to help understanding of urbanization 
process of the Montréal CMA. The population data were released every 5 years by Statistics Canada (2011). These data were thus used to analyse the relationship between urban expansion and population; in addition, both Consumer Price Index (CPI) and Industrial Production Price Index (CPPI) were acquired from Statistics Canada to explore their potential relationships with urban expansion. A set of full-colour QuickBird 0.6m resolution digital orthoimages in 2006 were provided by the Geospatial Centre, University of Waterloo as a reference map for accuracy assessment after image classification. Moreover, Google Earth very high resolution imagery for the Montréal CMA in 2015 was also used as reference map.

\subsection{Image classification}

Considering major land use categories within the Montréal CMA, and combined with spatial resolution of the imagery (i.e. $30 \mathrm{~m}$ ), six separate classes then were identified: residential, commercial, barren cropland, water body, forest and vegetation (Table 3 ).

Selecting an appropriate classification algorithm to classify the imagery can improve the overall accuracy, as the quality of classification results directly affect the performance of the change detection (Wang et al., 2015). Therefore, determining an appropriate classifier is significant. In this study, supervised classification methods and machine learning algorithms, including MLC, SVM, ANN and DT, were performed on both the 2006 and 2015 mosaicked images. Training samples were selected for the above six categories based on false colour composite of the reflective spectral bands. Based on the Jeffries-
Matusita (JM) distance report, which ranges from 0 to 2 and indicates an average distance between a pair of classes contributing to how accurate classification results will be, it can be therefore used to detect the spectral separability of training samples (Schmidt et al., 2003). If the value is asymptotic to 0 , the selected training samples are more polymerized.

Several indices were applied to generate DT algorithms to extract specified class from satellite imagery. Consequently, the Soil Adjusted Vegetation Index (SAVI) was used to extract vegetation information, as shown in equations (1) to (4); a Normalized Difference Bare Index (NDBI) was applied to select built-up areas; a Modified Normalized Difference Index (MNDWI) was presented to delineate open water features; and a Normalized Difference Bare Index (NDBal) for the bare land (Hua et al., 2012) was also used.

$$
\begin{aligned}
& N D B I=\frac{M I R-N I R}{M I R+N I R} \\
& S A V I=\frac{(N I R-R e d)(1+l)}{N I R+R e d+l} \\
& M N D W I=\frac{G R E E N-M I R}{G R E E N+M I R} \\
& N D B a l=\frac{d_{M I R}-d_{T I R}}{d_{M I R}+d_{T I R}}
\end{aligned}
$$

where $M I R$ and NIR represent the spectral reflectance in the TM and ETM+ green and mid-infrared bands; $d_{M I R}$ and $d_{T I R}$

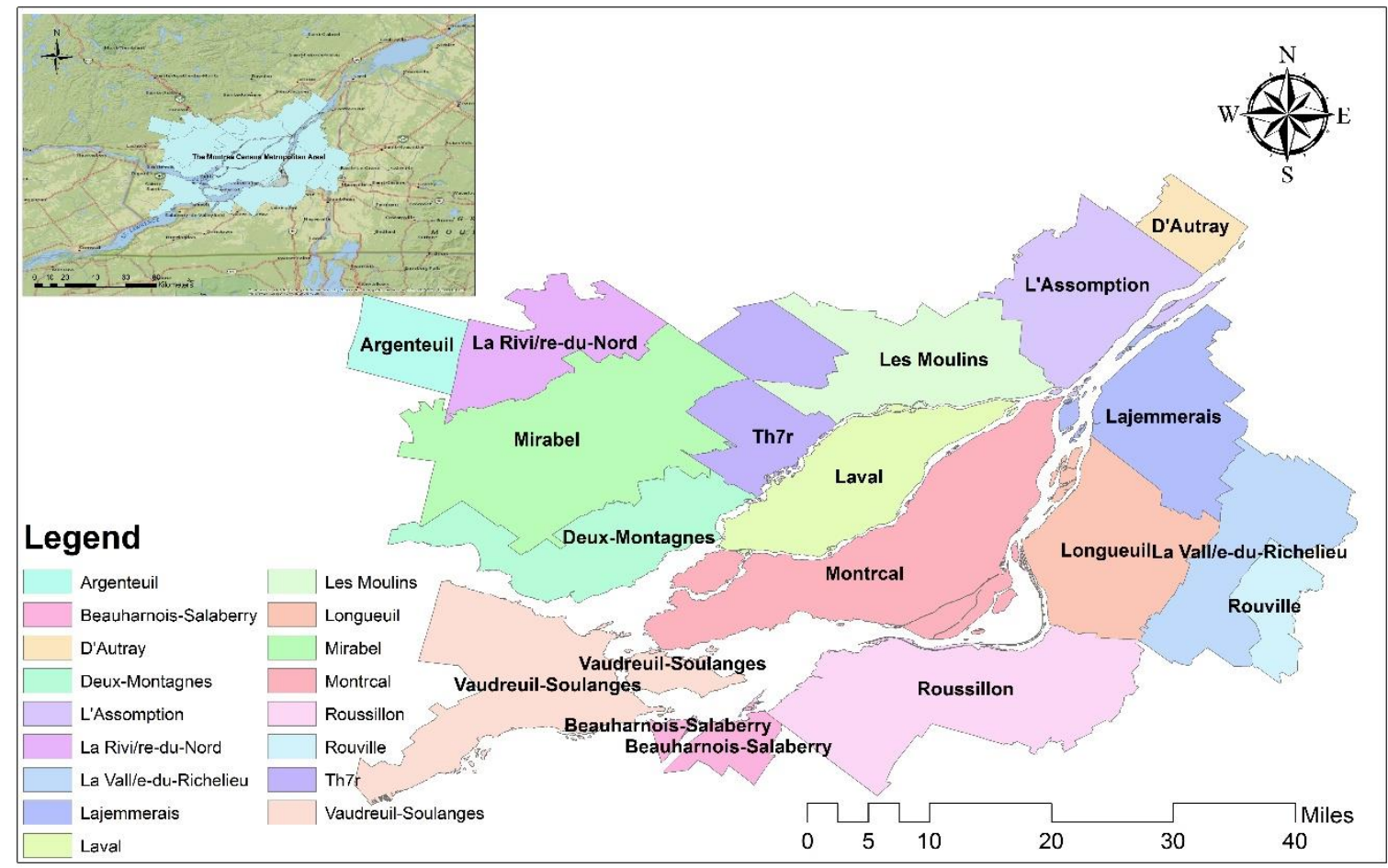

Fig. 1. Study area - The Montréal Census Metropolitan Area (CMA) 
Table 1. Introduction of the sensors used in this study

\begin{tabular}{|c|c|c|c|c|c|}
\hline \multirow{3}{*}{$\begin{array}{l}\text { Sensor } \\
\text { Landsat-5 } \\
\text { (TM) }\end{array}$} & \multirow{3}{*}{$\begin{array}{c}\text { Repeating cycle } \\
16 \text {-days }\end{array}$} & \multirow{2}{*}{$\begin{array}{l}\text { Band } \\
\text { Blue }\end{array}$} & \multirow{2}{*}{$\begin{array}{c}\text { Spatial Resolution(m) } \\
30\end{array}$} & \multicolumn{2}{|c|}{ Spectral coverage(um) } \\
\hline & & & & $0.45-0.52$ & \\
\hline & & Green & 30 & $0.52-0.60$ & \\
\hline & & Red & 30 & $0.63-0.69$ & \\
\hline & & Near-Infrared(IR) & 30 & $0.76-0.90$ & $1.55-1.75$ \\
\hline & & Mid-Infrared & 30 & $2.08-2.35$ & \\
\hline Landsat-5 & 16-days & Green & 60 & $0.5-0.6$ & \\
\hline \multirow{2}{*}{ (MSS) } & & Red & 60 & $0.6-0.7$ & \\
\hline & & Near-Infrared & 60 & $0.7-0.8$ & $0.8-1.1$ \\
\hline Landsat-7 & 16-days & Blue & 30 & $0.45-0.52$ & \\
\hline \multirow[t]{5}{*}{ (ETM+) } & & Green & 30 & $0.53-0.61$ & \\
\hline & & Red & 30 & $0.63-0.69$ & \\
\hline & & Near-Infrared(IR) & 30 & $0.78-0.90$ & \\
\hline & & Shortwave Infrared & 30 & $1.55-1.75$ & $2.09-2.35$ \\
\hline & & Panchromatic(Pan) & 15 & $0.52-0.90$ & \\
\hline Landsat8 & 16-days & Coastal & 30 & $0.435-0.451$ & \\
\hline \multirow[t]{7}{*}{ (OLI) } & & Blue & 30 & $0.452-0.512$ & \\
\hline & & Green & 30 & $0.533-0.590$ & \\
\hline & & Red & 30 & $0.636-0.673$ & \\
\hline & & NIR & 30 & $0.961-0.879$ & \\
\hline & & SWIR & 30 & $1.566-1.651$ & $2.109-2.294$ \\
\hline & & Pan & 15 & $0.503-0.676$ & \\
\hline & & Cirrus & 30 & $1.363-1.384$ & \\
\hline
\end{tabular}

Table 2. Satellite imagery with 5-year intervals used in this study

\begin{tabular}{|c|c|c|c|c|c|c|c|c|c|c|c|c|c|}
\hline \multicolumn{2}{|c|}{$1970 \mathrm{~s}$} & \multicolumn{4}{|c|}{$1980 \mathrm{~s}$} & \multicolumn{2}{|c|}{$1990 \mathrm{~s}$} & \multicolumn{3}{|c|}{$2000 \mathrm{~s}$} & \multicolumn{3}{|c|}{$2010 \mathrm{~s}$} \\
\hline & 1975 & 1980 & 1984 & 1985 & 1989 & 1990 & 1995 & 2000 & 2001 & 2006 & 2010 & 2011 & 2015 \\
\hline \multicolumn{14}{|l|}{ January } \\
\hline \multicolumn{14}{|l|}{ February } \\
\hline \multicolumn{14}{|l|}{ March } \\
\hline \multicolumn{14}{|l|}{ April } \\
\hline May & $05-21$ & & & & & & & & & & & & $05-06$ \\
\hline June & & & & $06-10$ & & & $06-23$ & & 06.08 & $06-27$ & & & \\
\hline July & & $07-10$ & $07-17$ & & & & & & & & $07-27$ & $07-14$ & \\
\hline August & & & & & $08-18$ & $08-14$ & $08-19$ & & & & & & \\
\hline September & & & & & & & & $09-25$ & & & & & $09-27$ \\
\hline October & & & & & & & & & & $10-01$ & & & \\
\hline \multicolumn{14}{|l|}{ November } \\
\hline \multicolumn{14}{|l|}{ December } \\
\hline Table key: & & Landsat5 TM & & & Lands & ETM+ & & Landsat8 OLI & & & Scenes used i & ange det & \\
\hline
\end{tabular}

Table 3. Classification categories and descriptions

\begin{tabular}{cc}
\hline Land cover/use types & Descriptions \\
\hline Residential & residential areas \\
Commercial & commercial sites \\
barren cropland & exposed soils, landfill sites, and areas of active excavation \\
water body & river, permenent open water, lakes, ponds and reservoirs \\
forest & deciduous forest, mixed forest lands, conifer and plams \\
vegetation & agricultural area, crop fields, fallow lands and vegetable lands \\
\hline
\end{tabular}

indicate the original raw digital numbers value in the TM/ETM+ mid-infrared and thermal infrared bands; and $l$ is soil adjusted factor, ranging in between 0 and 1 . In this case, we choose 0.5 to avoid the influence of different backgrounds. After image classification, a $3 \times 3$ majority filter is applied in order to eliminate the salt-and-pepper noise to improve classification accuracy (Wang et al., 2015).

After classification, accuracy assessment is generated for all classified imagery to assess the classification accuracy based on testing samples. Congalton and Green (1999) indicated that the testing sample size with a minimum of 50 samples for each class should be selected in terms of cost-effectiveness. In addition, both QuickBird imagery for 2006 and Google Earth imagery for 2015 were used to randomly select testing samples over 600 pixels (100 samples for each Level-2 class) in order to obtain reliable accuracy assessment for both years. Moreover, selected samples are manually validated. The error matrices therefore are generated, which contain the overall accuracy, the user's accuracy and the producer's accuracy (Congalton, 1991). The user's accuracy means the probability that a pixel is class A given that the classifier has determined the pixel into class A, while the producer's accuracy indicates the probability that the classifier has labeled a pixel into class A given that the ground truth is class A (Jensen, 2004).

\subsection{Change detection}

The post-classification comparison change detection technique is applied to detect urban expansion patterns over past 40 years. 
Thematic maps (Alphan et al., 2009) are then built based on separately classified multi-temporal imagery, and comparison between the classified images can be implemented in terms of per-pixel basis. This technique can provide detailed "from - to" information for each class in the process of urbanization (Jensen, 2004). Since we only would like to examine urban expansion patterns, the classified classes are merged into the following two main categories before applying the change detection technique: the urban area and the non-urban area, which can avoid the influences of misclassification or classification errors. Urban expansion then can be analysed based on bi-temporal and multi-temporal change detection maps.

\subsection{Urban expansion statistical analysis}

Wang (2015) indicated that both urban expansion rate and urban expansion spatial structure can be varying across time. In this study, as shown in Eq. (5), we determine the rate of urban expansion using the Land Use Change Index (LUCI) presented by Haregeweyn (2012), which can be a significant index to assess urban expansion.

$$
L U C I=\frac{U_{a}-U_{b}}{T * U_{b}}
$$

where $U_{a}$ represents the area of urban at Time a; $U_{b}$ represents the area of urban at Time $b$; $T$ is the time period between Time a and Time $b$. LUCI then can describe annual rate of urban areas if T's unit is in years. Consequently, the correlation between the urban areas and population can be calculated using Pearson correlation coefficient analysis (Wang, 2015).

Table 4. Accuracy assessment comparison among different classifiers for the 2006 imagery

\begin{tabular}{|c|c|c|c|c|c|c|c|c|}
\hline \multirow{2}{*}{$\begin{array}{c}\text { JUN-27-2006 } \\
\text { Level-2 category }\end{array}$} & \multicolumn{2}{|c|}{ MLC } & \multicolumn{2}{|c|}{ SVM } & \multicolumn{2}{|c|}{ ANN } & \multicolumn{2}{|c|}{$\overline{D T}$} \\
\hline & $P A$ & $\mathrm{UA}$ & $P A$ & UA & $P A$ & UA & $\overline{P A}$ & $U A$ \\
\hline Vegetation & 98.63 & 90.79 & 91.83 & 97.93 & 97.14 & 98.61 & & \\
\hline Forest & 92.87 & 94.09 & 99.44 & 95.26 & 99.39 & 98.38 & 96.39 & 99.02 \\
\hline Water & 89.31 & 100.00 & 99.67 & 99.97 & 99.64 & 99.97 & 94.26 & 94.43 \\
\hline Barren cropland & 94.62 & 98.76 & 93.90 & 98.19 & 94.74 & 99.30 & 79.69 & 86.52 \\
\hline Residential & 96.88 & 92.78 & 94.99 & 94.35 & 93.81 & 95.79 & 83.68 & 74.26 \\
\hline Commercial & 91.43 & 83.42 & 95.46 & 87.87 & 98.64 & 85.39 & 83.68 & 74.26 \\
\hline Overall Accuracy(\%) & \multicolumn{2}{|c|}{93.7850} & \multirow{2}{*}{\multicolumn{2}{|c|}{96.2619}} & \multicolumn{2}{|c|}{97.2573} & \multicolumn{2}{|c|}{89.3514} \\
\hline Kappa Coefficient & \multicolumn{2}{|c|}{0.9242} & & & \multicolumn{2}{|c|}{0.9665} & \multicolumn{2}{|c|}{0.8548} \\
\hline
\end{tabular}

\section{RESULTS AND DISCUSSION}

\subsection{Accuracy assessment}

Error matrices were generated to assess the accuracy of classified imagery based on four different classification approaches (i.e., MLC, SVM, ANN and DT) to determine an appropriate classifier over the study time period. As shown in Table 4, the MLC achieved an overall accuracy of $93.79 \%$. In contrast, SVM had an overall accuracy of $96.26 \%$, and the ANN's overall accuracy was the highest value of $97.26 \%$. These three classifiers performed better than DT's overall accuracy of $89.35 \%$. Both user's and producer's accuracies in commercial, barren cropland and vegetation in ANN were slightly better than the results from other classifiers. Thus, ANN classifier was chosen to perform image classification for the remaining imagery. To reduce misclassification, several classified categories were combined together into either urban area or non-urban area.

\subsection{Change detection maps and analysis}

As shown in Fig. 2, the bi-temporal change detection map indicated an increase in urban area in the Montréal CMA from $628 \mathrm{~km}^{2}$ in 1975 to $1554 \mathrm{~km}^{2}$ in 2015 . In addition, extracting and overlaying the urban area of the multi-temporal classified imagery, the 10 year intervals urban expansion change map was generated (Figure 3). According to Fig. 2 and Fig. 3, there were two main spatial urban expansion patterns in the Montréal CMA: centric expansion mode, in which the urban area expands from urban centres to surrounding non-urban areas by a series of concentric circles (Burgess, 2008); ribbon expansion mode, in which urban area grows along major river banks (e.g., St. Lawrence River) and lakeshores (e.g., Lake of Two Mountains). The Montréal CMA mainly expanded outward from the city of Montreal and along St. Lawrence River. Moreover, several major regional city centres, such as Laval, Roussillon, and Deux- Montagnes, also experienced rapid urbanization process within over past decades. As shown in Figure 3, many regional

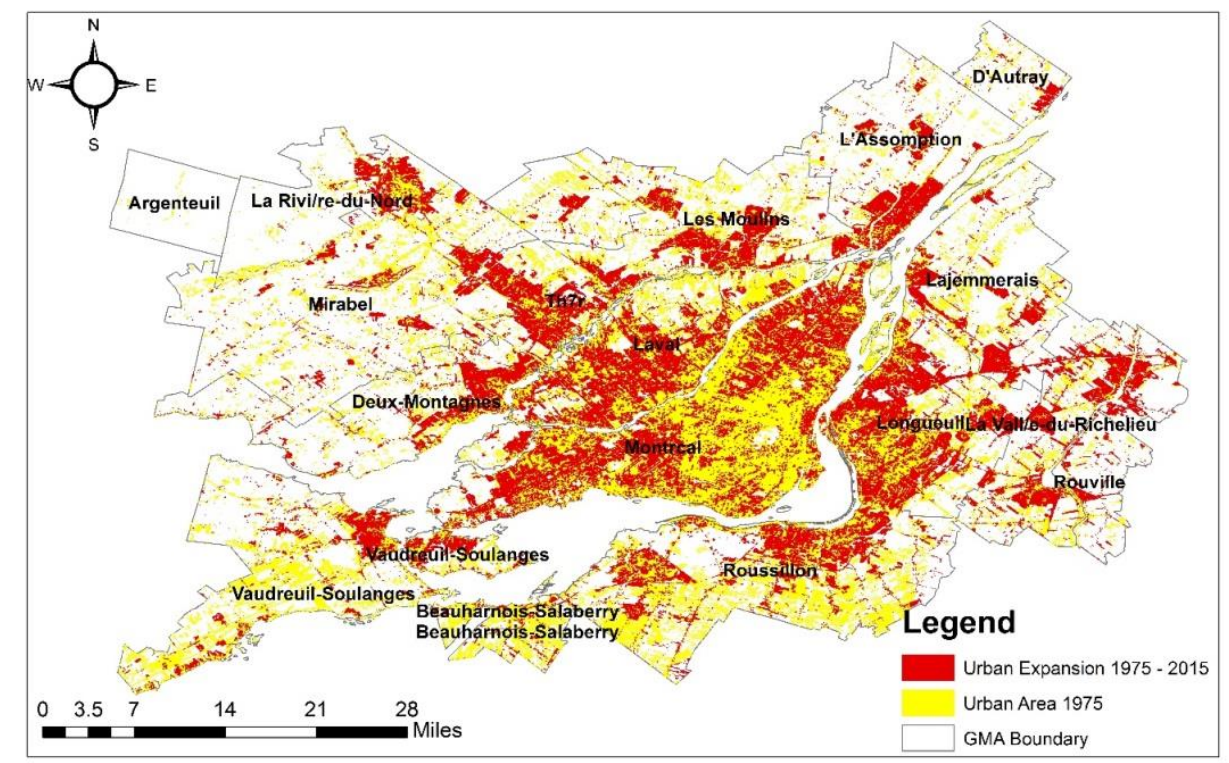

Fig. 2. Urbanization process change map for the Montréal CMA from 1975 to 2015 


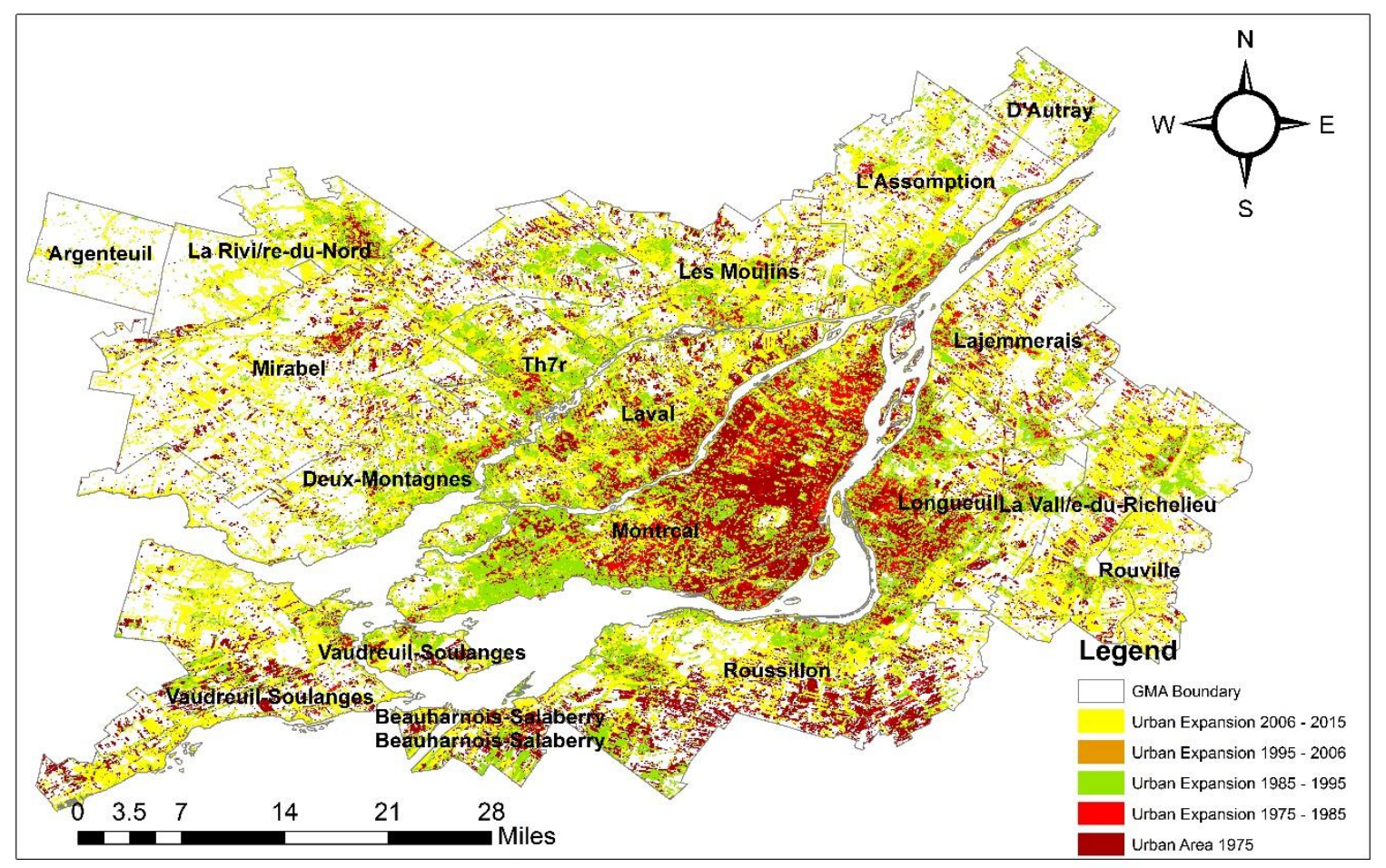

Fig. 3. Urbanization multi-temporal change map for the Montréal CMA from 1975 to 2015 with 10-year intervals

Table 5. Annual urban growth rate from 1975 to 2015 in the Montréal CMA

\begin{tabular}{lcccccccc}
\hline & $1975-1980$ & $1980-1985$ & $1985-1990$ & $1990-1995$ & $1995-2000$ & $2000-2006$ & $2006-2010$ & $2010-2015$ \\
\cline { 2 - 9 } Annual Growth Rate $(\%)$ & -1.4 & 4.1 & 3.9 & 2.5 & 4.6 & 0.8 & 0.1 & 1.7 \\
\hline${ }^{*}$ Mean aunnal growth rate $(\%)=1.6$ & & & & & & & & \\
\hline
\end{tabular}

centres were located in isolation, and major cities can be identified clearly. From 1975 to 1985 , areas around the city of Montreal experienced a significant expansion along their boundaries with Montreal. In the 1990's, the regions of Laval, Longueuil, and Terrebonne expanded outward rapidly. All these regions developed from their region centres. After 2000, both regions of Laval's and Montreal's urban expansion rate began to slow down, while outside areas (e.g., Mirabel and La Rivi) had an increasingly expansion rate of urban areas. From 2006 to 2015, the most considerable expansion occurred in both southwest and northwest regions of the Montréal CMA. Therefore, some small regions connected with other cities after 40 years of urbanization process, such as Mirabel and Les Moulins. Furthermore, some cities located both along St. Lawrence River and near Lake of Two Mountains, such as Longueuil and Vaudreuil-Soulanges, had a considerable development.

Overall, the urban areas in the Montréal CMA expanded outward from major regional centres, especially from the city of Montreal, and also along St. Lawrence River.

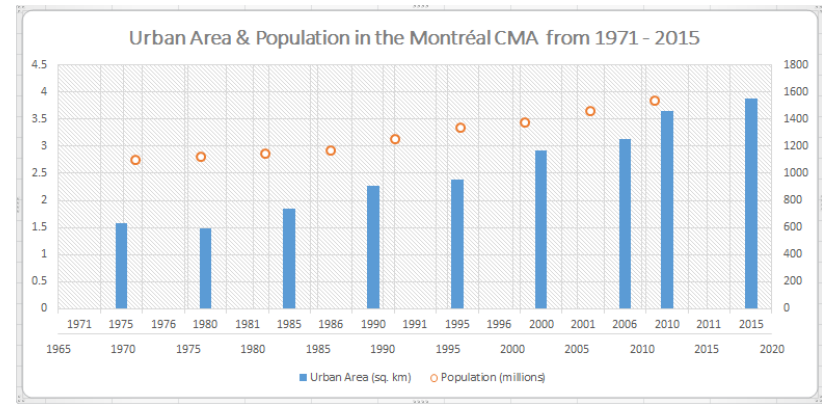

Fig. 4. Urban area and population statistics in the Montréal CMA 1975-2015

\subsection{Statistical analysis of urban expansion and driving force analysis}

As shown in Table 5, the mean annual growth rate of urban expansion in the Montréal CMA from 1975 to 2015 was $1.6 \%$. There were several significant urban expansion periods within the past 40 years. The periods among 1980-1985, 1985-1990, and $1995-2000$ experienced $4.1 \%, 3.9 \%$ and $4.6 \%$ in annual growth rate of urban area, respectively. A decrease in urban area period occurring in between 1975 to 1980 may result in image 
misclassification, since these images were obtained from Landsat-1 with 60 metres resolution and only 4 bands were available for the classification. From 2006 to 2010, the Montréal CMA experienced a lower annual growth rate of $0.1 \%$ in urbanization process, which may be due to low urban expansion rate in this period or lower classification accuracy of both imagery.

To reveal the relationship between urban growth rate and population, urban area was calculated from classified imagery with 5-year intervals from 1975 to 2015 to compare the correlation with census data of the Montréal CMA. As shown in Figure 4, both population and urban area experienced an increased tendency within this study time period. The chart indicated that urban expansion is positively correlated to population growth. The Pearson correlation coefficient (r) between urban area and population was $0.983(\mathrm{p}<0.01)$, which means strong correlation between these two variables.

When focused on three significant periods of urban expansion accompanied with the population growth over the same time, the mean annual population growth rate in the past 40 years was $0.98 \%$; however, the periods among 1981-1986, 1986-1991, and 1996-2001 experienced annual population growth rates of $0.43 \%, 1.41 \%$ and $0.6 \%$, respectively. It reflected that urban expansion was typically delayed by a few years followed by an obvious increase in population.

Bhatta (2010) indicated that urban expansion can be impacted on by a large amount of factors, such as population, economic development, and industrialisation. In addition, Industrial Production Price Index (CPPI) and Consumer Price Index (CPI) were also used to analyse their correlations with urban area; however, both CPPI and CPI mainly focus on economic prosperity, especially for inflation, they have small influences on urbanization process (Chen et al., 2013).

\section{CONCLUSION}

In this research, spatial and temporal dynamic changes of the urban area in the Montréal CMA have been successfully detected using Landsat series imagery. The selection of an appropriate classifier was a significant factor to reveal detailed urbanization process, which had impacts on the final change detection results. In our study, ANN was determined to be a superior classifier compared to other classification algorithms, such as MLC, SVM and DT. We found that the urban expansion mainly occurred in a centric expansion mode, in which the city expanded outward from the city of Montreal. The Montréal CMA also experienced an expansion mode along major river systems, such as St. Lawrence River. Furthermore, the urbanization process was strongly correlated with increased population. However, there are still some limitations in this research. For instance, only both QuickBird images in 2006 and Google Earth images in 2015 were available to select the training samples, accuracy assessment therefore may not be pretty reliable due to lack of reference maps.

In conclusion, Landsat series imagery can be successfully applied to identify the urban expansion patterns of the metropolitan areas for a long time period. The extent and spatial patterns of the Montréal CMA 's urban expansion were both identified quantitatively and qualitatively in this research. Moreover, integrating Landsat imagery and census data is feasible to analyse urban expansion in regional scales even global scales. Therefore, according to historical development patterns combined with current urban development policy, these results can be used by decision makers or regional governments to promote the Montréal CMA's economic development in the future.

\section{REFERENCES}

Al-Ahmadi, F. S., \& Hames, A. S. (2009). Comparison of four classification methods to extract land use and land cover from raw satellite images for some remote arid areas, Kingdom of Saudi Arabia. Earth Sciences, 20(1), 167-191.

Alphan, H., Doygun, H., \& Unlukaplan, Y. I. (2009). Postclassification comparison of land cover using multitemporal Landsat and ASTER imagery: the case of Kahramanmaraş, Turkey. Environmental monitoring and assessment, 151(1), 327-336.

Bagan, H., \& Yamagata, Y. (2012). Landsat analysis of urban growth: How Tokyo became the world's largest megacity during the last 40years. Remote Sensing of Environment, 127, 210-222.

Bhatta, B. 2010. Causes and Consequences of Urban Growth and Sprawl. In Analysis of Urban Growth and Sprawl from Remote Sensing Data. Springer Berlin Heidelberg.

Burgess, W.E. 2008. The Growth of the City: An Introduction to a Research Project. Urban Ecology, 4: 16-26.

Chen, M., Liu, W., \& Tao, X. (2013). Evolution and assessment on China's urbanization 1960-2010: under-urbanization or overurbanization? Habitat International, 38, 25-33.

Congalton, R. G., \& Green, K. (1999). Assessing the accuracy of remotely sensed data: principles and applications. Lewis Pub-lishers, Boca Raton, Fla.

Congalton, R. G. (1991). A review of assessing the accuracy of classifications of remotely sensed data. Remote sensing of environment, 37(1), 35-46.

Deilmai, B. R., Ahmad, B. B., \& Zabihi, H. (2014, June). Comparison of two Classification methods (MLC and SVM) to extract land use and land cover in Johor Malaysia. In IOP Conference Series: Earth and Environmental Science (Vol. 20, No. 1, p. 012052). IOP Publishing.

Dewan, A. M., \& Yamaguchi, Y. (2009). Land use and land cover change in Greater Dhaka, Bangladesh: Using remote sensing to promote sustainable urbanization. Applied Geography, 29(3), 390-401.

Erdas Inc., 1999. Erdas Field Guide. Erdas Inc., Atlanta, Georgia.

Erbek, F. S., Özkan, C., \& Taberner, M. (2004). Comparison of maximum likelihood classification method with supervised artificial neural network algorithms for land use activities. International Journal of Remote Sensing, 25(9), 1733-1748.

Gutman, G., Janetos, A., Justice, C., Moran, E., Mustard, J., Rindfuss, R., \& Turner, B. L. II, eds (2004) Land Change Science: Observing, Monitoring, and Understanding Trajectories of Change on the Earth's Surface. 
Gopal, S., \& Woodcock, C. (1996). Remote sensing of forest change using artificial neural networks. Geoscience and Remote Sensing, IEEE Transactions on, 34(2), 398-404.

Richards, J. (1999). Remote sensing digital image analysis (pp. 240-280). Berlin: Springer-Verlag.

Hua, L., Man, W., Wang, Q., \& Zhao, X. (2012). A new decision tree classification approach for extracting urban land from Landsat TM in a coastal city, China. In Information Science and Engineering (ISISE), 2012 International Symposium on (pp. 282-286). IEEE.

Huang, C., Davis, L. S., \& Townshend, J. R. G. (2002). An assessment of support vector machines for land cover classification. International Journal of Remote Sensing, 23(4), 725-749.

Haregeweyn, N., Fikadu, G., Tsunekawa, A., Tsubo, M., \& Meshesha, D. T. (2012). The dynamics of urban expansion and its impacts on land use/land cover change and small-scale farmers living near the urban fringe: A case study of Bahir Dar, Ethiopia. Landscape and Urban Planning, 106(2), 149-157.

Jensen, J.R., 2004. Introductory Digital Image Processing: A Remote Sensing Perspective. Third Edition. Prentice Hall, Toronto, Canada.

Joelsson, S. R., Benediktsson, J. A., \& Sveinsson, J. R. (2006). Random forest classification of remote sensing data. Signal and Image Processing for Remote Sensing, 978, 327-338.

Malczewski, J. (1999). GIS and multicriteria decision analysis. John Wiley \& Sons.

NASA, (2015), LANDSAT 7, retrieved from http://geo.arc.nasa.gov/sge/landsat/17.html

Otukei, J. R., \& Blaschke, T. (2010). Land cover change assessment using decision trees, support vector machines and maximum likelihood classification algorithms. International Journal of Applied Earth Observation and Geoinformation, 12, S27-S31.

Shalaby, A., \& Gad, A. (2010, June). Urban sprawl impact assessment on the fertile agricultural land of Egypt using remote sensing and digital soil database, case study: Qalubiya

Governorate. In US Egypt Workshop on Space Technology and Geoinformation for Sustainable Development, Cairo, Egypt (pp. 14-17).

Squires, G. D., \& Kubrin, C. E. (2005). Privileged places: Race, uneven development and the geography of opportunity in urban America. Urban Studies, 42(1), 47-68.

Schneider, A. 2012. Monitoring land cover change in urban and peri-urban areas using dense time stacks of Landsat satellite data and a data mining approach. Remote Sensing of Environment. 124: 689-704.

Schmidt, K. S., \& Skidmore, A. K. (2003). Spectral discrimination of vegetation types in a coastal wetland. Remote sensing of Environment, 85(1), 92-108.

Stan, A.I. 2013. Morphological Patterns of Urban Sprawl
Territories. Urbanism. Arhitectur `a. Constructii. 4(4): 11-24. Statistics Canada. 2011. Retrieved from: http://www 12.statcan.gc.ca/census-recensement/index-eng.cfm?MM

Tuia, D., Pacifici, F., Kanevski, M., \& Emery, W. J. (2009). Classification of very high spatial resolution imagery using mathematical morphology and support vector machines. Geoscience and Remote Sensing, IEEE Transactions on Geoscience and Remote Sensing, 47(11), 3866-3879.

Weng, Q. (2002). Land use change analysis in the Zhujiang Delta of China using satellite remote sensing, GIS and stochastic modelling. Journal of environmental management, 64(3), 273-284.

Wang, L., Li, W., Wang, S., \& Li, J. (2015). Examining Urban Expansion in the Greater Toronto Area Using Landsat Imagery from 1974-2014. GEOMATICA, 69(2), 161-172.

Yuan, F., Sawaya, K. E., Loeffelholz, B. C., \& Bauer, M. E. (2005). Land cover classification and change analysis of the Twin Cities (Minnesota) Metropolitan Area by multitemporal Landsat remote sensing. Remote sensing of Environment, 98(2), 317-328. 